\title{
Hoe (in)formeel leren assistenten in opleiding tot specialist hun taken en werkzaamheden uit te voeren? Eerste verkenningen.
}

\author{
A.R. Yedema • P.M. Boendermaker • J. Pols
}

Samenvatting Inleiding: Ook na de modernisering van de medische vervolgopleidingen zal het aandeel daarin van het zelfstandig werken in de patiëntenzorg ruim 90\% zijn. Literatuurstudies wijzen uit dat het leren uitvoeren van taken en werkzaamheden waarschijnlijk meer informeel dan formeel gebeurt. Om er bewust voor te kunnen kiezen dat zo te laten of het te veranderen, is antwoord nodig op de vraag: "in welke mate ervaren aios formele en informele leervormen bij het leren uitvoeren van hun taken en werkzaamheden?"

Methode: Het onderzoek is uitgevoerd met behulp van een elektronische enquête. Per taak werden zeven leervormen genoemd in een glijdende schaal van meer formele naar meer informele leervormen. Assistenten in opleiding tot specialist in Noord-Nederland is gevraagd per taak aan te geven welke leervormen zij daarbij ervaren.

Resultaten: Geen enkele taak wordt louter formeel of informeel geleerd. De aios ervaren:

1. meer informele dan formele leervormen.

2. bij de ene taak meer formele leervormen dan bij andere; bij taken uit het competentiegebied 'Medisch handelen' worden meer formele leervormen ervaren dan bij taken uit de andere competentiegebieden.

3. vaak de combinatie van de informele leervormen 'de kunst afkijken' en 'door te doen' met de formele leervorm 'supervisie door supervisor/opleider'.

Bovendien blijkt dat er grote verschillen zijn tussen de ervaren hoeveelheid leervormen per taak.

Conclusies: Met dit onderzoek is meer inzicht gekregen in de leersituatie van de aios op de werkplek. Het biedt opleiders handvatten voor enerzijds reflectie op hun opleiding en anderzijds voor gerichte veranderingen.

\section{Inleiding}

In de afgelopen jaren zijn na een lange voorbereidingsperiode de moderniseringsactiviteiten rond de medische vervolgopleidingen in een stroomversnelling geraakt. ${ }^{1}$ Met als resultaat dat assistenten in opleiding tot specialist (aios) vanaf medio 2007 vervolgopleidingen volgen die inhoudelijk en onderwijskundig vernieuwd zijn. ${ }^{2}$

Ook na introductie van de modernisering werken aios ruim $90 \%$ van hun opleidingstijd in de patiëntenzorg. ${ }^{3}$ Dat is goed bestede tijd, omdat van het zelfstandig uitvoeren van werkzaamheden een krachtig leereffect uitgaat. $^{4-6}$ Het biedt ook een grote uitdaging, omdat werkgerelateerd leren zich vaak informeel, dus spontaan en impliciet afspeelt. ${ }^{4-9}$ Dit informele karakter heeft wel tot gevolg dat er niet alleen gewenste, maar ook ongewenste leereffecten optreden. Het is de kunst om het werkgerelateerde leren zodanig te sturen dat het positieve rendement zo groot mogelijk is en de ongewenste leereffecten minimaal zijn. Aios en hun leermeesters (opleiders en supervisoren) spelen daarbij een belangrijke rol. Aios kunnen leren om zoveel mogelijk 'leer'profijt te trekken van hun taken en werkzaamheden door er kritisch op te reflecteren tijdens cursorisch onderwijs, maar ook tijdens het werk zelf. Leermeesters kunnen het positieve leereffect vergroten door zowel tijdens cursorisch onderwijs als op de werkvloer de kritische reflectie van aios te stimuleren. Dat laatste door als goed rolmodel te functioneren, aios bij de uitvoering van hun werkzaamheden te coachen en langzamerhand hun zelfstandigheid te laten toenemen. ${ }^{10}$

De genoemde ingrepen hebben allemaal te maken met een zekere vermindering van het informele karakter van het werkgerelateerde leren. Om te kunnen besluiten waar 
dat zinvol is, is het nodig om te weten welke taken en werkzaamheden aios verrichten en hoe formeel of informeel ze die leren uitvoeren. Dat maakt het mogelijk om er bewust voor te kiezen dat zo te laten of er iets aan te veranderen via cursorisch onderwijs of gerichte aandacht op de werkplek.

In een eerder gepubliceerd artikel rapporteerden we over de taken en werkzaamheden van aios. ${ }^{11}$ In dit artikel presenteren we het onderzoek waarmee we antwoord proberen te geven op de vraag: "In welke mate ervaren aios formele en informele leervormen bij het leren uitvoeren van hun taken en werkzaamheden?"

\section{Methode}

Definities van formeel en informeel leren

Er is geen discussie over het belang van

informeel leren voor werkgerelateerd leren, maar wel over de definitie ervan. In een recent artikel stelt Swanwick: "Informal learning then is a complex and heterogeneous concept, but is generally agreed to be central to any form of learning that takes place predominantly at work."12 En Bolhuis en Simons constateren: "Informeel leren is een containerbegrip waarbinnen een verscheidenheid aan mogelijke perspectieven denkbaar is". ${ }^{13}$ In de literatuur zijn dan ook diverse onderverdelingen te vinden die in de loop van de tijd voor informeel leren zijn voorgesteld. 6-9 1213 Op basis van de aangehaalde

literatuur is in dit onderzoek voor de volgende afbakening gekozen.

Formeel leren wordt door meerdere mensen georganiseerd, is gestructureerd en expliciet, wordt 'van bovenaf' opgelegd, is grotendeels 'off-the-job' en betreft het leren in een regulier schoolse setting. ${ }^{6-9} 12$ ${ }^{14}$ In de praktijk wordt formeel leren gekenmerkt door (landelijke) cursussen en trainingen, terugkomdagen, patiëntenbesprekingen, feedback van de leermeester en intervisie.

Informeel leren is nauwelijks georganiseerd en gestructureerd, wordt vaak op eigen initiatief (zelfstudie) gedaan, is soms impliciet, gebeurt meestal spontaan, gaat vaak door middel van ervaring en door te doen, is veelal 'on-the-job' en dus vaak niet aan een regulier schoolse setting gebonden. ${ }^{6-9} 1214$ Het kenmerk van informeel leren is het per toeval iets ontdekken, het van andere mensen afkijken (meelopen), het doen en uitproberen en het 'vragen, vragen en nog eens vragen' (uitspraak in ons onderzoek van een chirurg in opleiding).

De definities van formeel en informeel leren vormen uiteinden van een continuüm. In de praktijk zullen vooral combinaties van beide vormen voorkomen. ${ }^{14}$

Naarmate er aan meer criteria van de ene of andere leervorm wordt voldaan, zal er sprake zijn van meer formeel dan wel meer informeel leren.

\section{Gegevensverzameling}

Er is gebruik gemaakt van een elektronische enquête waarin aios werd gevraagd bij 59 taken en werkzaamheden aan te geven 1) met welke frequentie ze deze taak uitvoeren en 2) op welke manier ze deze taak leren. Over de frequentie waarin de taken worden uitgevoerd is eerder gerapporteerd.

${ }^{11}$ Tabel 5 geeft een overzicht van het takenpakket.

Om het continuüm van formeel en informeel leren te operationaliseren, zijn als antwoordmogelijkheden zeven situaties uit de praktijk van vervolgopleidingen gekozen. Ze vertegenwoordigen zeven leervormen, die lopen van van zeer formeel ('docentgebonden cursorisch onderwijs') naar zeer informeel leren ('door te doen/ervaren'), hetgeen werd bevestigd door een deskundige op het gebied van leren op de werkplek.* Na een pilotstudie onder zeven aios zijn de formuleringen van de leervormen op enkele punten aangepast (tabel 1 bevat de uiteindelijke formuleringen). De enquête bood de aios de mogelijkheid om bij elke taak meerdere leervormen in te vullen. Ze konden tevens suggesties doen voor aanvullende leervormen.

Het onderzoek is in april en mei 2004 uitgevoerd in de Onderwijs- en OpleidingsRegio (OOR) Noord- en Oost-Nederland, grofweg overeenkomend met de provincies Drenthe, Friesland, Groningen en Overijssel. De onderzoekspopulatie bestond uit alle (575) aios in de OOR die op dat moment een vervolgopleiding volgden 
Tabel 1 Voorbeeldberekening enquêteresultaten bij een taak met 168 respondenten.

\section{Taak:}

Voorbereiden op een consult/spreekuur/visite of huisbezoek.

Aantal respondenten 168

Leervorm $n$

1 Docentgebonden cursorisch onderwijs

2 Gestructureerde patiëntenbespreking $\quad 41$

3 Supervisie door de supervisor/opleider $\quad 120$

4 Zelfstudie

5 De kunst afkijken

6 Vragen stellen en beantwoorden van en aan collega's

Totaal

$\mathrm{n}=$ aantal respondenten dat deze leervorm ervaart.

$\%$ van het aantal respondenten. Bijvoorbeeld: 'Docentgebonden cursorisch onderwijs': $37 / 168=0,22$. Van de aios ervaart $22 \%$ deze leervorm. Totaal: $636 /(7 * 168)=0,54$. Van alle mogelijke leervormen $(7 * 168)$ ervaren aios $54 \%$.

De informele leervormen zijn cursief gedrukt.

Tabel 2 Samenstelling onderzoeksgroep naar specialisme en respons.

\begin{tabular}{llll}
\hline Specialisme & Onderzoeksgroep & \multicolumn{2}{c}{ Respons } \\
& & $\mathrm{n}$ & $\%$ \\
\hline Snijdend & 245 & 79 & 32 \\
Niet snijdend & 106 & 35 & 33 \\
Huisartsgeneeskundig & 129 & 38 & 29 \\
Sociaal geneeskundig & 95 & 15 & 16 \\
Totaal & 575 & 177 & 31 \\
\hline
\end{tabular}

tot medisch specialist, huisarts of sociaal geneeskundige.

Alle opleiders zijn verzocht medewerking te verlenen bij het verspreiden van de enquête. Via hun secretariaten is aan alle aios per e-mail het verzoek gedaan om mee te werken en is het internetadres van de definitieve enquête beschikbaar gesteld. $\mathrm{Na}$ twee en na vier weken zijn reminders verstuurd. Bij de laatste reminder is doorgevraagd naar de reden van eventuele non-respons.

\section{Verwerking gegevens}

Voor elke taak is uitgerekend welk percentage van het totaal aantal mogelijke leervormen werd ervaren. Bovendien is voor elke taak berekend hoeveel procent van de respondenten formeel en informeel leren heeft ervaren. In tabel 1 is een voorbeeldberekening opgenomen.

\section{Resultaten}

Respons en validiteit antwoordmogelijkheden

Alle opleiders verleenden hun medewerking aan de verspreiding van de enquête, behalve die van de Interne Geneeskunde en de Kindergeneeskunde die om hen moverende redenen afzagen van deelname. Van de 575 verzonden enquêtes zijn in totaal 196 enquêtes $(34,1 \%)$ geretourneerd. Daarvan zijn er 177 ingevuld en beoordeelbaar (respons 30,8\%). Van de resterende 19 enquêtes waren er vier niet beoordeelbaar en vijftien waren van aios die aangaven waarom zij de enquête niet invulden; het merendeel van hen (10) meldde tijdsgebrek (zie tabel 2). Er zijn negen suggesties gedaan voor aanvullende leervormen; dit betrof preciseringen van de in de enquête genoemde praktijksituaties.

\section{Ervaren leervormen}

Aios ervaren niet bij alle taken evenveel leervormen. Gemiddeld wordt $40 \%$ van de mogelijke leervormen ook daadwerkelijk ervaren, maar het percentage varieert van taak tot taak: minimaal is dat $22 \%$ bij het leren 'scheiden van werk en privé' en maximaal $64 \%$ bij het 'doen van consulten bij patiënten met een nieuw probleem'. Over de hele linie lijken aios meer leervormen te ervaren bij taken die direct samenhangen met het medisch handelen dan bij taken die daar minder mee samenhangen. Voor alle taken bij elkaar is de meest frequent ervaren leervorm 'door te doen' $(31 \%)$ en de minst frequente de 'gestructureerde patiëntenbesprekingen' (5\%) (zie tabel 3).

Per taak bestaan verschillen in de mate waarin aios de verschillende leervormen ervaren (zie tabel 4 en 5). Nadat de scheve verdeling van formele en informele leervormen 
Tabel 3 Frequentie en percentage van de zeven leervormen bij de 59 taken.

\begin{tabular}{lrr}
\hline Leervorm & $\mathrm{n}$ & $\%$ \\
\hline 7 Door te doen (ervaren) & 7.417 & 31 \\
3 Supervisie door supervisor/opleider & 4.091 & 17 \\
5 De kunst afkijken & 3.981 & 16 \\
6 Vragen stellen en beantwoorden aan en van collega's & 3.483 & 14 \\
4 Zelfstudie & 2.580 & 11 \\
1 Docentgebonden gestructureerd onderwijs & 1.480 & 6 \\
2 Gestructureerde patiëntenbesprekingen & 1.140 & 5 \\
Totaal & 24.172 & 100 \\
\hline
\end{tabular}

De informele leervormen zijn cursief gedrukt.

Tabel 4 Minimale en maximale frequentie waarin de zeven leervormen bij de 59 taken worden ervaren.

\begin{tabular}{lrr}
\hline Leervorm & Min. & Max. \\
\hline 1 Docentgebonden gestructureerd onderwijs & 0 & 50 \\
2 Gestructureerde patiëntenbesprekingen & 0 & 41 \\
3 Supervisie door supervisor/opleider & 0 & 41 \\
4 Zelfstudie & 43 & 88 \\
5 De kunst afkijken & 15 & 85 \\
6 Vragen stellen en beantwoorden aan en van collega's & 13 & 70 \\
7 Door te doen (ervaren) & 51 & 99 \\
\hline
\end{tabular}

De informele leervormen zijn cursief gedrukt.

over de antwoordcategorieën (resp. 3 en 4 items) is gecorrigeerd, blijkt gemiddeld $20 \%$ van de ervaren leervormen formeel $(1 \mathrm{t} / \mathrm{m} 3)$ en $80 \%$ informeel $(4 \mathrm{t} / \mathrm{m} 7)$ te zijn. Tussen taken bestaat een spreiding van 5 tot $35 \%$ formeel leren en van 65 tot $95 \%$ informeel leren. Bij sommige taken worden de drie formele leervormen nooit ervaren.

Van de drie taken die volgens eerder onderzoek het meest frequent worden uitgevoerd, ${ }^{11}$ staat in figuur 1 een overzicht met het percentage respondenten per leervorm. ${ }^{15}$

\section{Conclusies en beschouwing}

De uitkomsten van dit onderzoek bevestigen wat in de literatuur voor andere opleidingen al bekend is, namelijk dat geen enkele taak alleen formeel of informeel wordt geleerd. ${ }^{4}{ }^{12}$ Daarbij ervaren aios grote verschillen tussen de hoeveelheid leervormen per taak maar ook:

1. meer informele $(80 \%)$ dan formele $(20 \%)$ leermomenten.

2. bij de ene taak meer formele leervormen dan bij de andere; bij taken uit het competentiegebied 'Medisch handelen' worden meer formele leervormen ervaren dan bij taken uit de andere competentiegebieden.

3. vaak combinaties van de informele leervormen 'de kunst afkijken' en 'door te doen' met de formele leervorm 'supervisie door supervisor/opleider'.

Dit onderzoek geeft daarmee voor het eerst antwoord op de vraag in welke mate aios formele en informele leervormen ervaren bij het leren uitvoeren van hun taken en werkzaamheden. Om dit in beeld te brengen is een bruikbaar onderzoeksinstrument ontwikkeld. De validiteit van het instrument, dat op basis van theoretische modellen werd ontwikkeld en door experts werd getoetst, wordt bevestigd door het feit dat de gebruikers geen antwoordcategorieën bleken te missen. Bovendien stroken de uitkomsten/ bevindingen met wat er elders, zij het op andere terreinen, onderzocht is. ${ }^{12}$

De lage respons van 30,8\% (waarvan de precieze oorzaken onbekend zijn) en het ontbreken van de deelname van twee niet-snijdende specialismen, maken het onzeker of de bevindingen voor alle aios en alle opleidingen gelden. Het is dan ook niet zinvol om naar verschillen tussen (groepen) opleidingen of tussen de academische en perifere setting te zoeken, terwijl die wel te verwachten zijn. Op dit punt zal nader onderzoek noodzakelijk zijn. De keuze van het gebruikte instrument, tenslotte, brengt de beperking met zich mee dat het alleen een beeld geeft van het leren zoals dat door de respondenten is ervaren. Andere onderzoekmethoden, bijvoorbeeld observationeel onderzoek, kunnen eventueel andere leervormen opleveren.

De bevindingen dat aios bij de competentie 'Medisch handelen' meer formele leervormen ervaren en dat de hoeveelheid ervaren leervormen zeer verschilt per taak, vragen ons inziens om een nadere beschouwing. Een voor de hand liggende mogelijke verklaring vormt de (gepercipieerde) moeilijkheid van een taak en de mate waarin men die als cruciaal voor de beroepsuitoefening ervaart. 
Tabel 5 De 59 taken en werkzaamheden uit de enquête - naar frequentie waarin ze in de dagelijkse praktijk voorkomen ${ }^{11}-$ met per leervorm de percentages waarin die ervaren worden.

\begin{tabular}{|c|c|c|c|c|c|c|c|}
\hline Taken en werkzaamheden & & & & & Leer & rme & \\
\hline & $1^{*}$ & 2 & 3 & 4 & 5 & 6 & 7 \\
\hline 1 Samenwerken met ondersteunend personeel, zoals secretaresses & 2 & 0 & 14 & 7 & 34 & 30 & \\
\hline 2 Het medisch dossier van patiënten bijhouden & 9 & 11 & 51 & 18 & 68 & 39 & \\
\hline 3 Klachtgerichte anamnese afnemen & 43 & 26 & 58 & 49 & 55 & 41 & \\
\hline 4 Beleid opstellen voor een patiënt & 33 & 41 & 89 & 63 & 57 & 59 & \\
\hline 5 Lichamelijk onderzoek uitvoeren & 45 & 27 & 65 & 53 & 67 & 39 & 91 \\
\hline 6 Een algemene anamnese (screening) uitvoeren & 40 & 25 & 53 & 46 & 50 & 38 & 91 \\
\hline 7 De hulpvraag van een patiënt verhelderen & 50 & 21 & 51 & 30 & 56 & 38 & 91 \\
\hline 8 De resultaten van het aanvullend onderzoek interpreteren & 29 & 33 & 80 & 73 & 38 & 63 & 64 \\
\hline 9 Formulieren invullen en/of ondertekenen & 2 & 1 & 39 & 13 & 44 & 41 & 92 \\
\hline 10 Therapeutisch beleid uitvoeren & 36 & 34 & 90 & 69 & 60 & 55 & 8 \\
\hline 11 Aanvullend onderzoek aanvragen & 24 & 30 & 76 & 46 & 46 & 55 & 7 \\
\hline 12 Binnen de marges een planning maken van mijn werkzaamheden & 7 & 1 & 20 & 14 & 33 & 27 & 9 \\
\hline 13 Privé en werk van elkaar scheiden & 3 & 0 & 6 & 4 & 19 & 27 & \\
\hline 14 Mijn manier van werken aanpassen aan de persoonlijkheid van patiënten & 33 & 8 & 41 & 18 & 50 & 30 & \\
\hline 15 Consulten doen bij patiënten met een nieuw probleem & 31 & 35 & 91 & 71 & 68 & 63 & \\
\hline 16 Tegenover patiënten duidelijk maken wat ze wel en niet van mij kunnen verwachten & 26 & 12 & 55 & 14 & 51 & 44 & \\
\hline 17 Brieven schrijven en/of dicteren & 1 & 4 & 58 & 14 & 56 & 34 & 9 \\
\hline 18 Bij het bereiken van mijn medische bekwaamheid een supe & & & & & & & \\
\hline opleider raadplegen & 9 & 13 & 70 & 13 & 29 & 46 & \\
\hline 19 Samenwerken met verpleegkundigen & 1 & 6 & 26 & 9 & 43 & 30 & 9 \\
\hline 20 Voorbereiden op een consult/spreekuur/visite/huisbezoek & 22 & 24 & 71 & 60 & 60 & 55 & 81 \\
\hline 21 Omgaan met onverwachte gebeurtenissen die mijn planning in de war gooien & 2 & 1 & 19 & 8 & 24 & 26 & 9 \\
\hline 22 Zelf lacunes in mijn kennis en vaardigheden vaststellen & 25 & 16 & 49 & 57 & 17 & 35 & 71 \\
\hline 23 Zorgen dat ik de lacunes in mijn kennis en vaardigheden opvul & 30 & 20 & 49 & 88 & 21 & 50 & 51 \\
\hline 24 Een (andere) specialist in consult vragen & 8 & 17 & 65 & 24 & 41 & 56 & 79 \\
\hline 25 Medische verrichtingen uitvoeren & 25 & 6 & 46 & 24 & 75 & 35 & 9 \\
\hline 26 Consulten doen bij patiënten met langdurige/ chronische problematiek & 32 & 41 & 89 & 68 & 56 & 70 & 8 \\
\hline 27 Consulten doen bij patiënten met acute problematiek & 30 & 28 & 88 & 64 & 68 & 67 & 92 \\
\hline 28 De planning van mijn werkzaamheden afstemmen in overleg met collega's & 3 & 1 & 21 & 6 & 27 & 42 & 9. \\
\hline 29 De grenzen van mijn specialisme bewaken & 14 & 15 & 68 & 18 & 37 & 50 & \\
\hline 30 Zelf een patiënt overdragen & 1 & 10 & 40 & 14 & 67 & 30 & 94 \\
\hline 31 Patiëntgegevens verwerken m.b.v. een computerprogramma & 10 & 4 & 33 & 31 & 48 & 44 & 9 \\
\hline 32 Gesprekken voeren met familie en bekenden van patiënten & 17 & 12 & 46 & 14 & 65 & 37 & 9 \\
\hline 33 Voorbereiden van een patiëntenoverdracht & 1 & 18 & 40 & 19 & 57 & 32 & 9 \\
\hline 34 Met feedback omgaan die ik van collega's krijg & 14 & 7 & 18 & 9 & 16 & 28 & 8 \\
\hline 35 Samenwerken met paramedici & 3 & 7 & 20 & 11 & 36 & 28 & 98 \\
\hline 36 Samenwerken in een multidisciplinair team & 6 & 14 & 42 & 14 & 54 & 42 & 97 \\
\hline 37 Gesprekken voeren met patiënten voor het verkrijgen van toestemming & 14 & 8 & 48 & 16 & 52 & 40 & 9 \\
\hline 38 Mijn plaats als arts-assistent afbakenen binnen de hiërarchie van mijn afdeling/ praktijk & 2 & 2 & 17 & 6 & 34 & 44 & 97 \\
\hline 39 Co-assistenten superviseren & 3 & 4 & 18 & 13 & 47 & 32 & 96 \\
\hline 40 Diensten doen & 6 & 11 & 69 & 34 & 55 & 59 & 9 \\
\hline 41 Feedback geven op het handelen van collega's & 18 & 8 & 19 & 12 & 33 & 37 & 8 \\
\hline 42 De opname van een patiënt regelen & 4 & 5 & 48 & 16 & 54 & 50 & 92 \\
\hline 43 Omgaan met ongewenst gedrag van patiënten & 29 & 11 & 51 & 13 & 47 & 48 & 89 \\
\hline 44 Slecht nieuws gesprekken voeren met patiënten & 44 & 14 & 68 & 18 & 71 & 43 & 81 \\
\hline 45 Ingrepen/ operaties voorbereiden & 21 & 15 & 74 & 69 & 64 & 56 & 77 \\
\hline 46 Ingrepen/ operaties uitvoeren & 26 & 17 & 88 & 62 & 85 & 51 & 89 \\
\hline 47 Me aanpassen aan een nieuwe omgeving & 1 & 4 & 14 & 7 & 26 & 39 & 99 \\
\hline
\end{tabular}


Tabel 5 (continued)

\begin{tabular}{|c|c|c|c|c|c|c|c|}
\hline Taken en werkzaamheden & & & & & Leer & rme & \\
\hline 48 Een referaat houden & 22 & 15 & 41 & 57 & 71 & 32 & 95 \\
\hline 49 Veranderingen voorstellen die zorgen voor kwaliteitsverbetering van mijn werkomgeving & 4 & 4 & 13 & 11 & 16 & 31 & 92 \\
\hline 50 Jongerejaars arts-assistenten superviseren & 2 & 1 & 23 & 16 & 53 & 34 & 94 \\
\hline 51 Onderzoek doen & 21 & 0 & 63 & 53 & 38 & 39 & 94 \\
\hline 52 Leidinggeven aan een team & 6 & 4 & 39 & 15 & 59 & 29 & 98 \\
\hline 53 Lesgeven aan co-assistenten & 4 & 9 & 16 & 47 & 43 & 20 & 95 \\
\hline 54 Samenwerken met mensen die geestelijke ondersteuning bieden aan patiënten & 1 & 9 & 0 & 3 & 15 & 13 & 97 \\
\hline 55 Een artikel schrijven & 10 & 1 & 72 & 45 & 49 & 33 & 92 \\
\hline 56 Leidinggeven aan een afdeling/ praktijk & 10 & 8 & 45 & 12 & 61 & 37 & 94 \\
\hline 57 Lesgeven aan arts-assistenten & 29 & 7 & 20 & 45 & 53 & 29 & 93 \\
\hline 58 Gesprekken voeren met patiënten over euthanasie & 27 & 9 & 62 & 17 & 44 & 35 & 65 \\
\hline 59 Periodieke gezondheidskeuringen uitvoeren & 10 & 8 & 38 & 35 & 35 & 33 & 83 \\
\hline Overall & 17 & 13 & 47 & 30 & 47 & 41 & 89 \\
\hline
\end{tabular}

*Legenda: meer informele leervormen cursief;

$1=$ Docentgebonden cursorisch onderwijs; $2=$ Gestructureerde patiëntenbesprekingen; $3=$ Supervisie door supervisor $/$ opleider; $4=$ Zelfstudie; $5=$ De kunst afkijken; $6=$ Vragen stellen en beantwoorden aan en van collega's; 7 = Door te doen (ervaren).

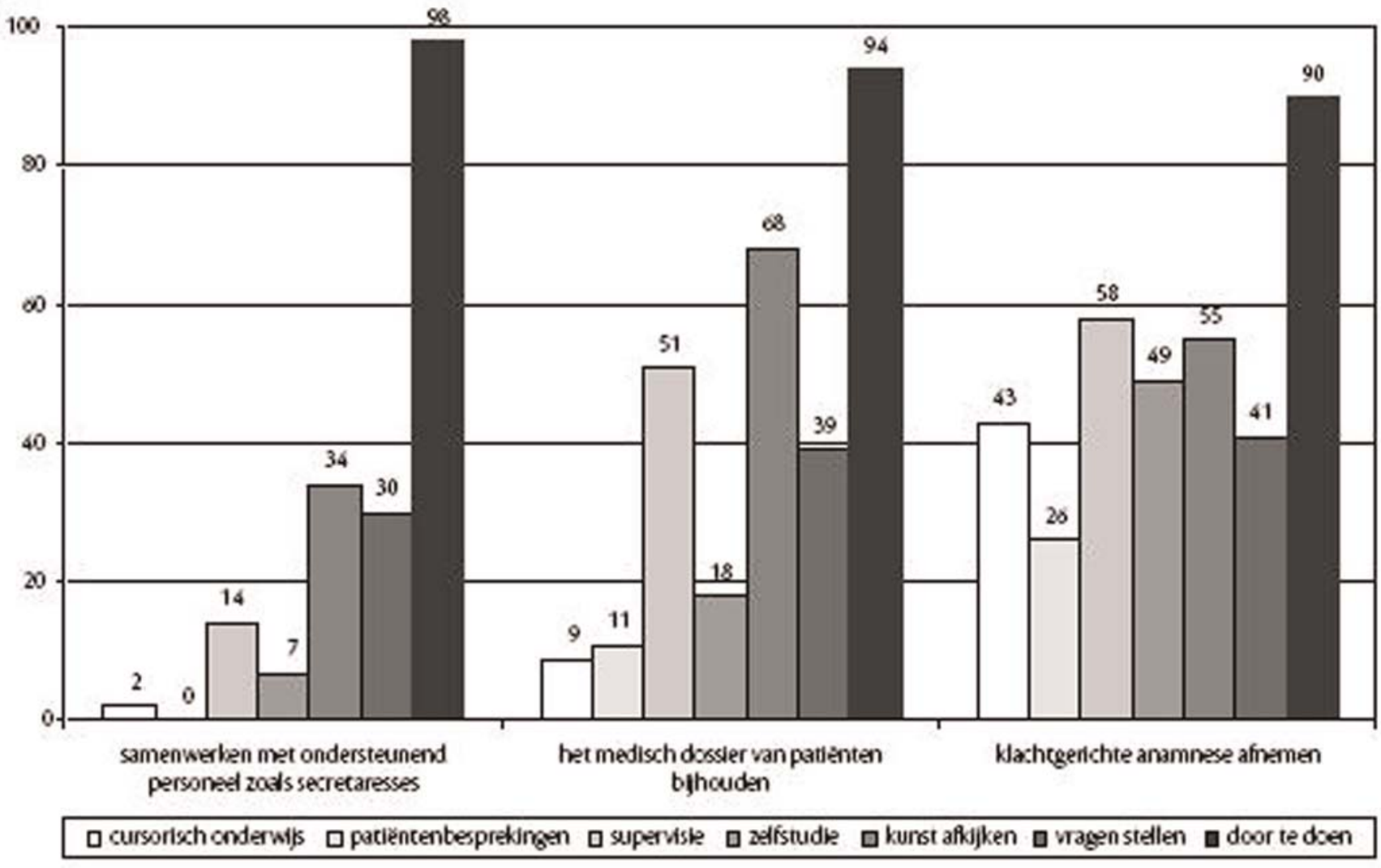

Figuur 1 De drie meest frequent uitgevoerde taken met per leervorm het percentage respondenten dat die leervorm ervaart bij het leren van de taak.

Bij taken die aios als moeilijk en/of cruciaal ervaren, zullen zij zich meer bewust zijn van hun leerproces en daardoor meer leervormen ervaren. Bij taken die ze zich gemakkelijk eigen (denken te) maken, zullen ze zich minder bewust zijn van hun leerproces en dus ook minder leervormen ervaren. Een dergelijke invloed gaat ook uit van de leermeesters. Die zullen bij de aios meer aandacht besteden aan taken die zij zelf zien als lastig en/of cruciaal voor de beroepsuitoefening, dan aan taken waarvoor dat niet geldt. De bevindingen rond de competentie 'Medisch handelen' en de voorbeelden uit figuur 1 lijken deze gedachtegang te ondersteunen. 
Ondanks de geplaatste kanttekeningen biedt ook dit verkennende onderzoek opleiders nu al praktische mogelijkheden. Met de uitkomsten kunnen zij in gesprek gaan met hun aios om erachter te komen in welke mate zij hun taken formeel of informeel leren, of ze behoefte hebben aan meer formelere leermomenten en of ze tevreden zijn met de huidige situatie. Dat maakt het mogelijk om er bewust voor te kiezen het opleidingsprogramma aan te passen. Of niet.

\section{Dankwoord}

De auteurs danken de aios. Hun medewerking was cruciaal voor dit onderzoek. Daarnaast zijn de auteurs dank verschuldigd aan dr. J. Onstenk (CINOP/ Hogeschool INHOLLAND) voor zijn hulp bij het uitwerken van het continuüm van formeel en informeel leren.

Belangenconflict: geen gemeld

Financiële ondersteuning: geen gemeld

\section{Summary}

Introduction: Workplace learning will remain the dominant method in Dutch postgraduate specialist training. When the current round of measures to modernise specialist training is completed, over $90 \%$ of training will consist of active participation in patient care. From the literature we know that learning in the workplace has formal and informal components. We investigated postgraduate trainees' perceptions regarding the distribution of formal and informal components in their programmes. The results may be used to evaluate whether there is a need for change in postgraduate training.

Method: Trainees were given an electronic questionnaire asking them to indicate for different tasks which of seven types of learning, ranging from highly formal to highly informal, they experienced.

Results: There was no task for which the trainees qualified their learning as exclusively formal or informal:

- Trainees experience more informal types of learning compared to formal ones.

- Formal learning varies across tasks with more formal learning being experienced in relation to 'clinical competence' compared to other competencies.

- Trainees frequently perceive a combination of 'learning by observation', 'learning by doing' and the type of formal learning that occurs during 'supervision by clinical teachers'.

Tasks and activities show substantial differences in the number of different types of learning experienced by trainees.

Conclusion: This study sheds light on the types of learning that occur during postgraduate specialist training. The results may help clinical teachers reflect on the training programmes and guide any changes in these programmes. (Yedema AR, Boendermaker PM,
Pols J. Formal and informal learning in postgraduate medical education. An exploratory study. Dutch Journal of Medical Education 2007;26(4):158-166.)

\section{Literatuur}

Bleker OP, Hoorntje JCA, Schelfhout VJ. Beter en leuker: CCMS ontvouwt plannen voor de vervolgopleiding van medisch specialisten. Med.Contact 2004;59(43):1692-5.

Stuurgroep Modernisering Opleidingen en Beroepsuitoefening in de Gezondheidszorg. Project "Modernisering Medische Vervolgopleidingen": ontwikkeling en implementatie van een vernieuwd opleidingstraject tot (medisch) specialist [projectplan] Utrecht: Stuurgroep MOBG, 2005. Beschikbaar op: www.medischevervolgopleidingen.nl//content/documenten/ documentatie/projectplan $\% 20 \mathrm{mmv}$.pdf [Bezocht op 10-052007].

Heineman O. Voordracht tijdens de presentatie van het eerste bestuur van het College voor de Beroepen en Opleidingen in de Gezondheidzorg (CBOG), 27 februari 2007. Beschikbaar op: www.medischevervolgopleidingen.nl/pages/content/S2/ nieuws56.aspx [Bezocht op 10-05-2007].

Onstenk JHAM. Lerend leren werken: brede vakbekwaamheid en de integratie van leren, werken en innoveren [dissertatie]. Delft: Eburon; 1997.

Bolhuis S. Leren en veranderen bij volwassenen, een nieuwe benadering. 2e druk. Bussum: Uitgeverij Coutinho; 2001.

Eraut M, Boulay B du. Developing the attributes of medical professional judgement and competence. University of Sussex: Institute of Education, 2000.

Becher T. Professional practices: commitment and capability in a changing environment. New Brunswick: Transaction Publishers, 1999.

Bolhuis S. Professioneel leren: wat is het en hoe bevorderen we het? Tijdschrift voor Medisch Onderwijs 2002;21(4):172-81.

Onderwijsraad. Werk maken van een leven lang leren. Den Haag: Drukkerij Artoos; 2003.

Irby DM. Teaching and Learning in Ambulatory Care Settings - A Thematic Review of the Literature. Acad Med 1995;70 (10):898-931.

Pols J, Yedema AR, Boendermaker PM. Een explorerend onderzoek naar het takenpakket van artsen in opleiding tot specialist. Tijdschrift voor Medisch Onderwijs 2005;24(5):220-9.

Bolhuis S, Simons PRJ. Leren en werken. Deventer: Kluwer Bedrijfswetenschappen, 1999.

Onstenk JHAM, Boogert K den. Profiel leercompetenties voor het beroepsonderwijs. Zoetermeer: CINOP; 2002.

Swanwick T. Informal learning in postgraduate medical education: from cognitivism to 'culturism'. Med Educ 2005;39(8):859-65.

Een tabel met alle resultaten is beschikbaar op: http://wencke4. housing.rug.nl/documenten/medici/Ontwikkelplatform/ Resultaten/YedemaA.R.htm 